\section{Quando os paradigmas mudam na saúde pública: o que muda na história?}

\section{When paradigms change in public health: what changes in history?}

\section{Guilherme Arantes Mello}

Professor, Departamento de Medicina Preventiva/ Universidade Federal de São Paulo; Programa de Pós-graduação em Saúde Coletiva/Universidade Católica de Santos.

Rua Botucatu, $740,4^{\circ}$ andar

04023-062 - São Paulo - SP - Brasil

gmello@unifesp.br

Recebido para publicação em abril de 2015.

Aprovado para publicação em outubro de 2015.

http://dx.doi.org/10.1590/S0104-59702017000200011
MELLO, Guilherme Arantes. Quando os paradigmas mudam na saúde pública: o que muda na história? História, Ciências, Saúde - Manguinhos, Rio de Janeiro, v.24, n.2, abr.jun. 2017, p.499-517.

Resumo

Trata-se de ensaio conceitual sobre a ideia de ruptura paradigmática e sua implicação na leitura histórica da saúde pública/coletiva, campo em que se confundem as dimensões política e científica. Um argumento inicial serve para esclarecer o caráter polissêmico e pré-conceitual de "paradigma", atento às implicações conceituais, mas reafirmando sua utilidade semântica. Segue com a discussão de rupturas essenciais e cumulativas, aplicada ao confronto da ruptura epistêmica promovida pelos centros de saúde distritais e idealização do movimento de reforma sanitária. Conclui pela dificuldade do paradigma "saúde coletiva" em sustentar sua independência discursiva, de modo que a difusão planetária da matriz discursiva dos centros de saúde pela Fundação Rockefeller ainda se configura como a última ruptura paradigmática holística da saúde pública brasileira.

Palavras-chave: história da saúde pública; reforma dos serviços de saúde; política; medicina preventiva.

\section{Abstract}

This conceptual essay investigates the idea of paradigmatic rupture and its implications in historical interpretations of public/ collective health, where the dimensions of politics and science intermingle. The polysemic and pre-conceptual nature of "paradigm" is clarified, taking account of the conceptual implications, while reaffirming their semantic usefulness. Essential and cumulative ruptures are discussed and applied to the confrontation of the epistemic rupture brought about by district health centers and the goals of the public health reform movement. The difficulty of the collective health paradigm in maintaining its discursive independence is presented, such that the global spread of the discursive matrix of health centers by the Rockefeller Foundation still constitutes the most recent holistic paradigmatic rupture in Brazilian public health.

Keywords: history of public health; health service reform; politics; preventive medicine. 
A inda na graduação, em tempos de iniciação científica, meu primeiro contato com o termo "paradigma" foi marcante, sobre o qual fluiu a encantadora impressão de que aquela palavra, com sua bela estética, conferia uma aura científica e de verdade a tudo o que tocava. Passado algum tempo, começaram a surgir indícios de que aquela sensação poderia não ter sido algo tão particular. Atkin (2002) colocou luz sobre a questão: o emprego da expressão "mudança de paradigma" havia disparado nos títulos de artigos no quarto de século precedente, ao que atribuiu à frenética busca por visibilidade dos textos - "paradigma" tornara-se uma espécie de pedra filosofal da ciência.

$\mathrm{Na}$ literatura científica, a rigor, o conceito de "paradigma" se refere quase que obrigatoriamente às "mudanças revolucionárias" nas ciências naturais vistas por Thomas Kuhn (2006a). Amplamente comentada, a ideia original versa sobre um ciclo de compartilhamento ordinário de tradições, regras e pressupostos científicos durante um período acumulativo denominado "ciência normal". De tempos em tempos, os programas científicos atravessariam crises de conhecimento com potencial de confrontar-lhes com limites insuperáveis, fronteira de particular representação no campo linguístico. A uma crise de tal magnitude não mais restariam adaptações cumulativas, senão soluções holísticas que abarcassem novos conjuntos de generalizações inter-relacionadas, por conseguinte trazendo consigo um novo léxico. Situação denominada "revolução científica", responsável por reiniciar todo o ciclo (Kuhn, 2006a).

Apesar dessa origem bastante precisa nas ciências naturais, há tempos a ideia de paradigma pode também ser encontrada reportando-se a toda uma gama de interesses teóricos sociais e políticos. Com o campo da saúde pública brasileira não foi diferente. A "retórica paradigmática" foi motivo de um ensaio de Paim e Almeida Filho (2000), no qual descortinam o caráter de slogan que a expressão acabou assumindo, com habitual conotação ideológica em substituição à científica.

A par da propriedade específica do texto, o problema com esse tipo de interpretação conceitual é não considerar devidamente a indissociabilidade entre ciência e política no universo da saúde pública - de forma que deve mesmo ser esperado que intencionalidades ideológicas estejam imiscuídas aos ideais científicos nos discursos de rupturas paradigmáticas nesse campo. Em outras palavras, faz pouco sentido o questionamento da propriedade do uso daquela expressão na saúde pública centrado em sua premissa filosófica; ainda mais quando considerada sua imprecisão original, como será tratado adiante.

O essencial encontra-se, isto sim, na apreensão do significado último que o recurso àquele conceito exprime a um enunciado que necessariamente transita entre o científico e o político. Isto é, o que dada ideia de ruptura paradigmática realmente representa em termos históricos no campo da saúde pública? Qual o corte de tempo envolvido, a polaridade e radicalidade desse novo paradigma?

Neste esclarecimento é antes preciso responder a que percurso levou uma leitura original do campo estrito das ciências naturais a se tornar ponto pacífico nas ciências sociais e discursos ideológicos?

Argumento, aqui, sobre essas questões e analiso a polaridade e radicalidade de duas das mais representativas ideias de ruptura paradigmática na saúde pública brasileira: o "centro de saúde distrital" e a "reforma sanitária". Atento à coetaneidade do tema em relação aos 
preceitos da história dos conceitos e ideias, aproveito do recurso didático de opor o científico/ saúde ${ }^{1}$ e o político/pública em matrizes discursivas polares, mesmo sabendo que o conceito de "saúde pública" é complexo, com enunciados políticos e científicos heterogêneos e sujeitos a uma infinitude de mesclas (Tarride, 1998).

\section{Paradigmas: científico ou político?}

A palavra "paradigma", em sua sinonímia de valor, modelo ou padrão, é antiga e aqui e ali pode ser encontrada na própria literatura sanitária brasileira muito anteriormente à década de 1960, quando toma os ares teóricos mais conhecidos: “Um estudo recente, que poderia servir de paradigma a outros que se fizesse" (Souza, 1938, p.270). Mas não se pode negar a intenção conceitual por trás de seu emprego nos textos técnicos atuais, de modo que o uso meramente corriqueiro tornou-se incomum a ponto de levar autores a explicitar quando da acepção pré-kuhniana, como pode ser visto em Lakatos (1998, p.24), Arouca (2003, p.41) e Paim $(1997$, p.11) - às vezes, quase que como solicitando permissão ao que seria o sentido de direito.

A realidade é que a citação de Kuhn (2006b, p.360) que se tornou clássica era apenas uma leitura inicial e restrita, desconhecendo mesmo o conceito de "paradigma" trabalhado anteriormente por Wittgenstein, como ele mesmo atesta. Desde o início, aquela proposição sofrera críticas incisivas relativas à imprecisão conceitual empregada (Masterman, 1979; Kuhn, 1979, 2006b), no que o autor tendeu a concordar: "Coincido com sua opinião [Masterman] de que o termo 'paradigma' aponta para o aspecto filosófico central do meu livro, mas o tratamento que ali se deu é muito confuso" (Kuhn, 1979, p.289; destaque no original). Reconheceu que talvez sua ideia de paradigma fosse mais bem definida pela escolha de alguma expressão alternativa, a exemplo de "matriz disciplinar" (Kuhn, 1979, p.335).

Em paralelo, o autor conta que se via surpreendido com interpretações ideológicas de sua proposição sobre revoluções paradigmáticas, equivocadamente transferidas para os efervescentes ideais político-revolucionários dos anos 1960 (fator que inclui como contribuinte para sua notoriedade teórica). ${ }^{2}$ A convicção do marxismo como campo científico adiciona mais um elemento a esse enredo. Franco concorrente de Kuhn no novo campo disciplinar, Imre Lakatos (1998, p.59) ilustra esse amálgama ao argumentar que a "crise kuhniana" não se comprometia com a direcionalidade do processo de ruptura, de modo que, se todos os astrônomos resolvessem se converter à astrologia, isto não deixaria de representar uma "revolução normal", independente de seu direcionamento "degenerativo". Uma característica que, segundo descreve, favoreceu "a popularidade não intencional da sua teoria entre a Nova Esquerda ativamente empenhada na preparação da 'revolução' de 1984" (Lakatos, 1998, p.75, nota 113; destaque no original).

De outro lado, a realidade é que o cartesianismo de Kuhn (2006b, p.121), advindo da formação em física, aos poucos se dobrou à sua incursão pela filosofia e pela história, obrigando-o a redimensionar seu campo visual para também abarcar as humanidades: "penso agora que enfatizamos demasiadamente o aspecto empírico de nosso empreendimento (uma epistemologia evolucionária não precisa ser uma epistemologia naturalizada)". 
O percurso semântico da expressão "ruptura paradigmática" entre as ciências naturais e as humanidades, e daí para a leitura ideológica e o próprio senso comum, ficou assim favorecido por vários caminhos confluentes: certa correspondência esperada sobre a dinâmica de rupturas sistemáticas entre os diversos campos de conhecimento; um tanto de fermento ideológico sobre a ideia de ruptura revolucionária; mas sobretudo pela ausência de conteúdo teórico suficientemente específico para alçá-la à condição definitiva de conceito, muito menos circunscrito a um campo particular da ciência.

Sem o necessário corpo teórico, a linguagem viva apenas reafirmou o autogoverno das palavras e ideias: "Se pudesse, eu chamaria paradigmas a estas soluções de problemas, pois foram elas que me levaram a escolher o termo em primeiro lugar. Tendo perdido o controle da palavra, eu os descreverei, daqui por diante, como exemplares" (Kuhn, 1979, p.335).

Mas, de fato, a difusividade universal da ideia de mudança paradigmática não deve ser desconsiderada, ou diminuída em importância - apenas relativizada e desgarrada da obrigatoriedade conceitual estrita sobre aquele Kuhn original. Na realidade, o êxito da expressão é revelador da lacuna linguística contemporânea de um termo específico que expressasse - ou professasse - com a devida ênfase novos tempos, novos marcos intelectuais do campo científico e tecnológico, mas também político. Vivacidade cujo discernimento libera as amarras pseudocientíficas e permite que pensamentos originais inclinados para diferentes polos do conhecimento, como o "paradigma emergente" de Boaventura Santos (2006); ou o "paradigma indiciário" de Ginzburg (1989); ou ainda o "paradigma do pensamento complexo" de Morin (2011), não se vejam compelidos à salvaguarda específica de Kuhn. Sem entrar em méritos, Morin nos lembra da limitação histórica das leituras de Kuhn, Poper, Lakatos, Feyerabend e outros, ao não alcançarem a sistêmica e a complexidade.

Em um termo provisório à questão semântica, e contrariando qualquer aspiração purista sobre os ideais científicos, é possível enfim assumir a coerência da palavra "paradigma", e suas expressões derivadas, em seu amplo significado de rupturas nos diversos campos do saber. Em outros termos, rupturas que se fazem representar no plano estritamente intelectual, na materialidade tecnológica ou em processos. Novos paradigmas cuja radicalidade os caracteriza como "essenciais" ou "holísticos" ou "revolucionários" - culminando em especiação (ver adiante) ou apenas cumulativos, com peso variável sobre o conhecimento pregresso. Na saúde pública, ruptura paradigmática que ora pende para o processo político, ora para a natureza científica do objeto.

Com isso, o parecer de um "novo paradigma" se vê desprendido daquela pretensão exclusivamente homérica para espelhar o que de fato o é no cotidiano: a percepção de marcos simbólicos de intensidades diversas em um campo disciplinar, tecnológico ou político. Como consequência direta no objeto deste estudo, a identificação de qualquer ruptura paradigmática deixa de ter um comportamento semântico autoexplicativo, e essa insuficiência passa a exigir da leitura histórica uma coleção de elementos que permita relativizar o grau dessa representação na própria genealogia da área. 


\section{Justificativa sobre o olhar conceitual}

A ruptura paradigmática revolucionária define uma cisão penetrante em seu objeto que se representa, em última análise, no surgimento de termos/conceitos icônicos e originais que redefinem o discurso e, por conseguinte, a própria construção da realidade. Nessa lógica, uma mudança paradigmática essencial deve também ser reconhecida, em conclusão, como uma alteração original do discurso.

Tendo o novo léxico científico-tecnológico como representante último de uma ruptura paradigmática incisiva, a análise histórica dos conceitos contribui com uma leitura privilegiada da questão. Em confronto com ideias ou discurso, a historicidade das palavras proporciona o aprofundamento do contexto e significados sociais: "Uma história das ideias não nos diz nada do significado destas ou sobre as alterações semânticas ocorridas. Mas quando uma ideia se converte em conceito, a totalidade dos contextos de experiência e significados sociopolíticos aparece" (Bentivoglio, 2010, p.122).

Para Reinhart Koselleck (1992), nome obrigatório nesse domínio, a análise dos movimentos sincrônico e diacrônico envolvidos é inevitável para a compreensão semântica dos conceitos, refletindo-se na pertinência das categorias históricas de continuidade e ruptura (embora de utilidade seletiva a seu ver). Atenta para o fato de que rupturas são francamente mais comuns na história política - com usual caráter destrutivo e agudo sobre as continuidades -, ao inverso do campo linguístico, no qual as transformações são mais lentas e graduais. Cita como exemplo o processo de unificação da Alemanha, com sua ruptura política incisiva facilmente identificável, ao passo que a integração social e cultural se prolonga durante décadas (Koselleck, 1992).

De valor heurístico, em outro plano, Araújo (maio 2008, p.48) argumenta não ser suficiente o mero entendimento da linguagem como "constituída e constituinte da realidade", mas propriamente como instrumentos cognitivos integrantes essenciais dos processos produtivos. Nesse raciocínio, o conceito ganha sentido materializável; sempre numa dinâmica de reajustes com a realidade, no que assume a posição de Koselleck quanto à circularidade entre os conceitos e o real (Araújo, maio 2008). Aqui traz uma perspectiva esclarecedora sobre a percepção dos olhos coetâneos na análise de objetos com pouco distanciamento histórico por exemplo, sobre a ideia de reforma sanitária: "Devemos diferenciar 'transição' enquanto categoria da análise historiográfica - que independe da percepção dos atores e pode identificar certos fenômenos estruturais - de transição enquanto uma sensação coeva aos sujeitos históricos em tela" (p.53; destaque no original). Do diálogo dessas posições depreende-se a visibilidade mais clara e imediata das rupturas do plano político, ao passo que por vezes enganosamente óbvia aos partícipes e contemporâneos. Em contrapartida, à percepção de rupturas epistêmicas se exige maior distanciamento histórico (que pode ser representado, por exemplo, no tempo decorrido entre os estudos seminais e seu reconhecimento Nobel). Logo, a radicalidade política pode ser observada com grande antecedência, mas somente o tempo permite analisar a radicalidade epistêmica. 


\section{Ruptura por acúmulo (empurrada) ou por intencionalidade (puxada)?}

Uma questão central a ser observada no campo histórico da saúde pública é o sentido do vetor de surgimento dos novos ícones linguísticos advindos de suas rupturas (de polo científico ou político): seja "empurrado" pelo esgotamento do léxico científico normal, ou, em sentido inverso, "puxado" pela intencionalidade política.

O vetor de direcionamento científico pode ser representado pela ideia de "especiação científica" concebida por Kuhn (2006b) ${ }^{3}$ em substituição ao "paradigma revolucionário". Nela, os léxicos estabelecidos confrontam sua insuficiência para representação e construção intelectual dos novos fenômenos; apuro que força nova especiação disciplinar com seu novo léxico (termos/conceitos). Sua face mais aparente no cotidiano acadêmico revela-se nas progressivas divisões disciplinares observadas nos departamentos universitários ao longo de determinado tempo. Foi o que ocorreu no campo da física clássica com o surgimento da física quântica, ou com a biologia molecular forçando o surgimento de novos conceitos na área da genética, a exemplo de "ubiquitinação".

Em meados da década de 1970, a propagação do conceito de "sistemas" no planejamento da saúde pública, desde o século XIX tratados como "serviços", exemplifica um novo léxico empurrado pela acumulação científica no campo da sistêmica e cibernética - embora não tenha alcançado a dimensão holística visualizada na época (Chaves, 1972). Mais atualmente podem ser aventados como possibilidades de rupturas importantes os conceitos dos sistemas complexos (Plsek, 2003) ou connected health (Iglehart, 2014), mas lhes falta ainda distância histórica para análise.

Inversamente, no vetor de direcionamento político, a definição de um novo léxico resulta não da ruptura por acúmulo teórico propriamente, mas da intencionalidade em reconformar as práticas estabelecidas por meio da sobreposição de um novo senso ideológico, cuja consecução de seu paradigma exige um novo discurso/léxico hegemônico e norteador. Em seu cunho teleológico, as novas palavras icônicas surgem imaturas de conteúdo teórico específico, de modo que esse tipo de ruptura se faz partindo de um léxico preconceitual. Talvez seu exemplo mais atual esteja representado na ideia de pesquisa translacional (Zerhouni, 2005) - sem obviamente relegar o acúmulo científico também envolvido.

Em resumo, no primeiro caso, aproveitando a imagem do darwinismo científico analisada por Kuhn (2006b), o novo paradigma surge "empurrado" pela construção de conceitos originais resultantes de grande quantidade de conhecimentos acumulados; e os termos surgidos simbolizariam uma ramificação ou "especiação" do ideário anterior. Por semelhança, em seu sentido mais político, o novo paradigma emerge então "puxado" por um télos norteador (práxis), no qual o novo léxico preconceitual deriva de uma estratégia induzida de ruptura paradigmática com a acumulação normal - uma forma de superação/ anulação do ideário e conceitos anteriores. Esse novo léxico alia o desafio de difundir-se no senso comum ao mesmo tempo que elabora seu conteúdo técnico-científico específico e original (mais uma vez, não é real essa separação estrita de político e científico, senão como recurso didático. Assumir tal possibilidade significaria a defesa da ciência como um campo social imune às ideologias). 


\section{Rupturas paradigmáticas na saúde pública brasileira}

Aqui, podemos partir das perguntas mais elementares: que eventos representariam rupturas paradigmáticas na saúde pública brasileira? E qual a radicalidade e que dinâmica as impulsionaram?

Em texto anterior, assinalei para ser detalhada em outro momento a proposição de Winslow (1923) sobre três grandes fases da saúde pública internacional - o que provavelmente seria lido hoje apropriadamente como rupturas paradigmáticas essenciais da saúde pública. Configuravam-se no "saneamento empírico" operado em torno de 1840-1890; seguido de uma "era bacteriológica" baseada na aplicação científica da bacteriologia no controle de doenças infectocontagiosas, que teria perdurado isoladamente até a primeira década do século XX; e, finalmente, o período moderno que se seguiu fundado na "educação sanitária" e "centros de saúde distritais" (CS). Assumi que essas fases, de clara enunciação científica, poderiam ser vinculadas às três grandes fases da periodização política da medicina social de Foucault (2000): medicina de Estado; medicina urbana das cidades; e medicina dos pobres e da força de trabalho. Realidade brasileira que se revela no antes e depois da ruptura bacteriológica francesa com a atuação de Emílio Ribas e Oswaldo Cruz no começo do século XX, duas décadas depois superada pelos ideais "científicos" dos centros de saúde distritais norte-americanos (Mello, Viana, 2011).

A denominação "era bacteriológica" traz implícita a influência do pensamento científico pasteuriano - maior destaque entre as grandes instituições de pesquisa e saúde surgidas dessa acumulação científica. A inserção de Oswaldo Cruz na saúde pública do país teve este claro sentido científico: um médico periférico e desconhecido que apregoava as modernas técnicas aplicadas por Finlay em Cuba no controle epidemiológico da febre amarela (Fraga, 2005). Como lembra Winslow (1923), o acúmulo de conhecimento foi de tal forma avassalador que essa fase é responsável por definir a organização sanitária como campo científico. A população de países periféricos como o Brasil, assoladas por epidemias, rapidamente introjetara o novo paradigma no senso comum, fosse pelas decisões políticas de saneamento relacionadas aos custos comerciais da situação epidemiológica ou pela percepção da interdependência sanitária: a doença "que pega" (Hochman, 1998).

Mas a ruptura dos ideais norte-americanos dos centros de saúde em detrimento do pensamento bacteriológico francês foi ainda mais profunda, incisiva, abrangente e estável. Fruto de uma dinâmica muito diversa da anterior, está bem documentado seu claro planejamento institucional. Ruptura que, sob o olhar político, foi caracterizada pela transição das atividades sanitárias sobre as cidades para atuação sobre os indivíduos - o que, segundo Foucault (2000), gera um equívoco de interpretação como passagem da atuação coletiva para a individual. Ao contrário, defende, teria se tratado de uma mudança muito mais efetiva de controle coletivo por meio do indivíduo.

A partir da segunda década do século XX, a difusão do novo pensamento norte-americano de organização sanitária rapidamente tomou contornos planetários pelas mãos da Fundação Rockefeller, justificada em termos de filantropia de larga escala com vistas à disseminação dos novos ideais científicos da saúde pública em benefício dos povos. 
De fato, configurou-se como uma ruptura epistêmica revolucionária tão drástica, poderosa, difusa e enraizada que ainda permanece como principal alicerce do pensamento sanitário contemporâneo nas Américas. Esse argumento central do ensaio significa assumir que não houve outras rupturas revolucionárias, holísticas, posteriores. Sob a perspectiva conceitual, é o mesmo que admitir que aquele léxico introduzido principalmente a partir dos anos 1920 mantém sua essência preservada, naturalmente com ganho paulatino de abrangência, elaboração e densidade (Mello, Viana, 2011, 2012; Mello, 2012). A dedução reversa apregoa que o conjunto de rupturas paradigmáticas menores que se seguiram representa, antes de tudo, paradigmas cumulativos. Mesmo tentativas mais extremas não conseguiram se sustentar fora dos limites daquela matriz discursiva fluida e cada vez mais abrangente tecida na periferia por fios roquefelerianos, um tempo depois também fornecidos pela Fundação Kellogg. Em suas entrelinhas conceituais, desvela-se uma matriz discursiva liberal por excelência (Marinho, 2001) - cuja dimensão clínica se entrelaça ao novo léxico "revolucionário" desencadeado pelo relatório Flexner (1910), que no campo médico reproduziu de igual modo o aniquilamento internacional da influência francesa na medicina.

O plano internacional, refletido no país, apresenta vários exemplos de rupturas cumulativas de marcante significação para o campo da saúde pública. Um novo paradigma foi estabelecido pela educação médica desde os anos 1940, fortemente embalado pelo conceito de "medicina integral" (Mello, Viana, 2012). Sua repercussão latino-americana é bem conhecida nos famosos seminários de Viña del Mar (Chile) e Tehuacán (México), nos anos de 1955 e 1956 (Mascarenhas, Wilson, Bourroul, 1961; Feuerwerker, 1998). Outro paradigma foi estabelecido pela introdução do planejamento em saúde, e na recuperação da proposta do relatório Dawson de hierarquização dos serviços em nível primário, secundário e terciário (Informe..., 1964).

Também não se pode negar a representação paradigmática a uma série de ocorrências específicas da saúde pública brasileira. Entre elas, às formulações operadas pela política varguista na conformação de uma burocracia técnica e de uma rede básica (Fonseca, 2007); especialmente por meio da criação e atuação do Serviço de Saúde Pública (Sesp) (Campos, A., 2006) - uma nova "era" na visão do eminente professor Reinaldo Ramos (1972); o otimismo sanitário dos anos 1950 (Lima, Fonseca, Hochman, 2005); as reformas administrativas do final da década de 1960 (Mello, Bonfim, 2015); a hegemonia do discurso e conceitos da educação médica na década seguinte (Feuerweker, 1998); e mesmo a ruptura representada pelo Programa Saúde da Família (PSF) (Viana, Dal Poz, 2004). O que deve ser pesado é que representam, em conjunto, características claramente cumulativas sobre o ideário anterior, e não de rompimento. Assim também se definem as repercussões da conferência de Alma-Ata em 1978 (Mello, Fontanella, Demarzo, 2009). No campo da assistência médica, todo esse caminhar acompanha as rupturas da "hygiene" (e higiene), para medicina integral, medicina preventiva, medicina geral comunitária e, enfim, medicina de família e comunidade. Arouca (2003) e Paim, Almeida Filho (1998) fornecem ótimas leituras sincrônicas sobre essa questão.

Sem dúvida, o sanitarismo brasileiro tem no ideário do denominado movimento da reforma sanitária, advindo desde os anos 1970, uma de suas mais significativas rupturas paradigmáticas. Naqueles primórdios, a repressão do regime militar sobre as áreas sociais clássicas contribuiu para canalizar forças progressistas no setor saúde, fazendo emergir um "pensamento radical de classe média" (Candido, 1988) na vanguarda da saúde pública no país. A brilhante arqueologia 
do "dilema preventivista" (Arouca, 2003) viria fornecer a centelha epistemológica necessária à pretendida ruptura de aspiração holística. Seguia uma mobilização penetrante, em extensa rede latino-americana operada por intelectuais de esquerda, despertada pela atuação de Juan Cesar García em seus anos de Organização Pan-americana de Saúde (Opas) (Nunes, 1989).

Congregado inicialmente sob a batuta do Centro Brasileiro de Estudos de Saúde (Cebes), uma intelectualidade coletiva orgânica enfim se define na Associação Brasileira de Pósgraduação em Saúde Coletiva (Abrasco), progressivamente entabulada pela ideia-força da reforma sanitária. Uma crítica progressista mordaz aflora, com particular repercussão sobre a área de planejamento em saúde (Gallo, 1995; Testa, 1992); e, na sequência, a ideia da reforma sanitária se vê definitivamente atraída pelos referenciais marxistas italianos de Giovanni Berlinguer (Berlinguer, Teixeira, Campos, 1988).

Configuradas essas duas rupturas maiores, aparentemente polares, da saúde pública brasileira, é necessário um olhar mais detalhado em ordem de relativizar sua radicalidade paradigmática.

\section{O centro de saúde distrital}

A pergunta básica para a qual talvez não seja possível uma resposta definitiva diz respeito à essência primaz da atuação da Fundação Rockefeller na saúde pública internacional: filantropia científica de larga escala ou dominação ideológica de um campo científico e econômico? A única certeza, tratando-se de saúde pública, é que ciência e ideologia caminharam de mãos dadas. De um lado é realidade que a aposta "científica" inicial - que atualmente seria mais apropriadamente vista como "tecnológica" - mostrou acertos e potencial, a ponto de dominar a cena até os dias atuais. De outro, é inegável o contexto militar, assim como a seletividade de atuação sobre problemas relacionados à força de trabalho (Brown, 1976; Nunes, 1989; Vasconcellos, 1995; Marinho, 2001).

Detalhado em outro momento, em suas origens, os CS não contavam com conceitos bem estabelecidos (Mello, Viana, 2011). Uma imaturidade teórica que se revela na própria condição de que a Escola de Higiene da Universidade Johns Hopkins e seu famoso doutoramento na nova saúde pública tiveram início em 1917, apenas um ano antes da inauguração do Instituto de Higiene de São Paulo. A "nova era" trazia um conjunto de ideias imaturas, como coordenação, saúde coletiva, exame médico periódico, tempo integral, descentralização e, a principal delas, educação sanitária (Souza, Vieira, 1936), tendo sido necessárias décadas para essa maturação conceitual (Mello, Viana, 2012).

Embora não se deva subestimar sua capacidade de acúmulo científico - considere-se, por exemplo, que a Sociedade de Saúde Pública nos EUA já nos anos 1920 somava cerca de cinco mil membros -, fato é que aquele acúmulo absolutamente não teria sido suficiente para uma revolução paradigmática tão devastadora e penetrante de modo a rapidamente se estabelecer uma nova ordem mundial na saúde pública. Em que pese não responder à pergunta inicialmente formulada, não deve restar dúvida de que tal dominância foi tributária de forte intencionalidade política em difundir os novos referenciais norte-americanos, com maciço investimento econômico (Figura 1). 


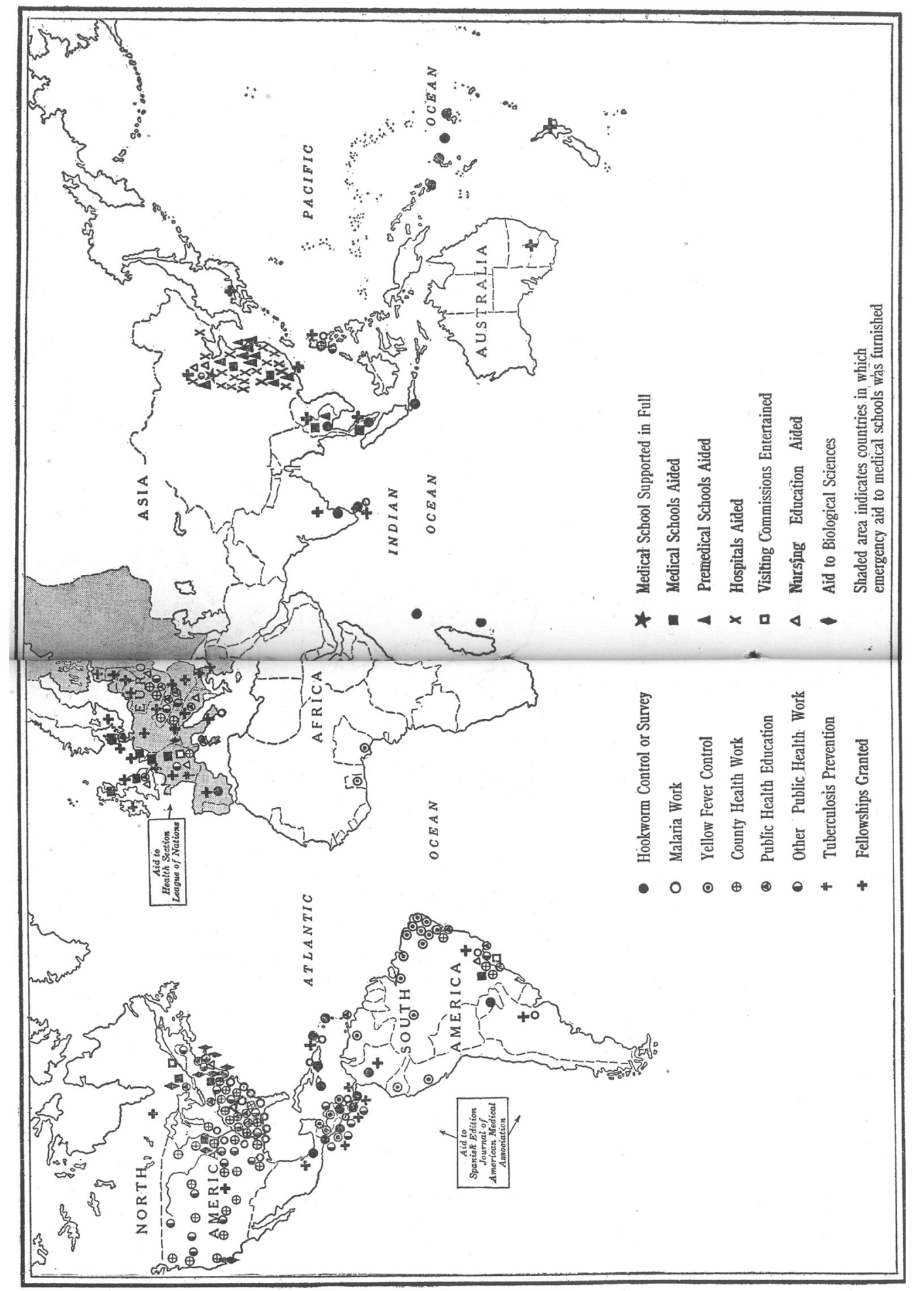

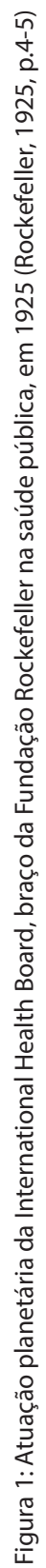


Entrementes, Johns Hopkins operou num ritmo disciplinar muito acelerado, ao se fixar como nó de uma ampla rede internacional baseada na atuação Rockefeller e no retorno centrípeto proporcionado pelos milhares de bolsistas internacionais que cursaram doutoramento na instituição. Apenas entre os sanitaristas brasileiros são contabilizadas mais de três centenas desses bolsistas até meados do século XX (Castro Santos, Faria, 2002). Uma situação que possibilitou o acesso e processamento privilegiado de um enorme consolidado de informações; do controle devolutivo nos planos científico e ideológico; estabelecimento de laços afetivos e identificação de grupo; assim como a aculturação e proficiência do idioma entre as novas lideranças sanitárias mundiais. De sorte que, a partir dos anos 1920, a saúde pública internacional passa muito rapidamente a definir como modelo e referência os autores e publicações norte-americanos - presságio de uma dominância absoluta do processo.

No Brasil, os CS chegam pelas mãos de Geraldo de Paula Souza, refinado membro da aristocracia paulistana que acabaria por se tornar importante embaixador da Fundação Rockefeller na saúde internacional. Arauto da nova ordem mundial na saúde pública, foi dele a honra, dividida com colega chinês, de apresentar o protocolo de criação da Organização Mundial da Saúde (Mello, 2012) - dirigida nos vinte anos iniciais pelo brasileiro Marcolino Candau. O pacote de escolha de São Paulo como demonstração da "nova ciência" para os demais países latino-americanos era acompanhada de nova e suntuosa sede no alto do bairro de Araçá - hoje Faculdade de Saúde Pública da Universidade de São Paulo -, a exemplo de outros países (Figura 2). Carlos Chagas havia se esforçado em vão em negociações com a Fundação Rockefeller para levar o novo instituto de higiene para Manguinhos (Castro Santos, Faria, 2006) - justamente aquele que representava o modelo francês a ser superado.

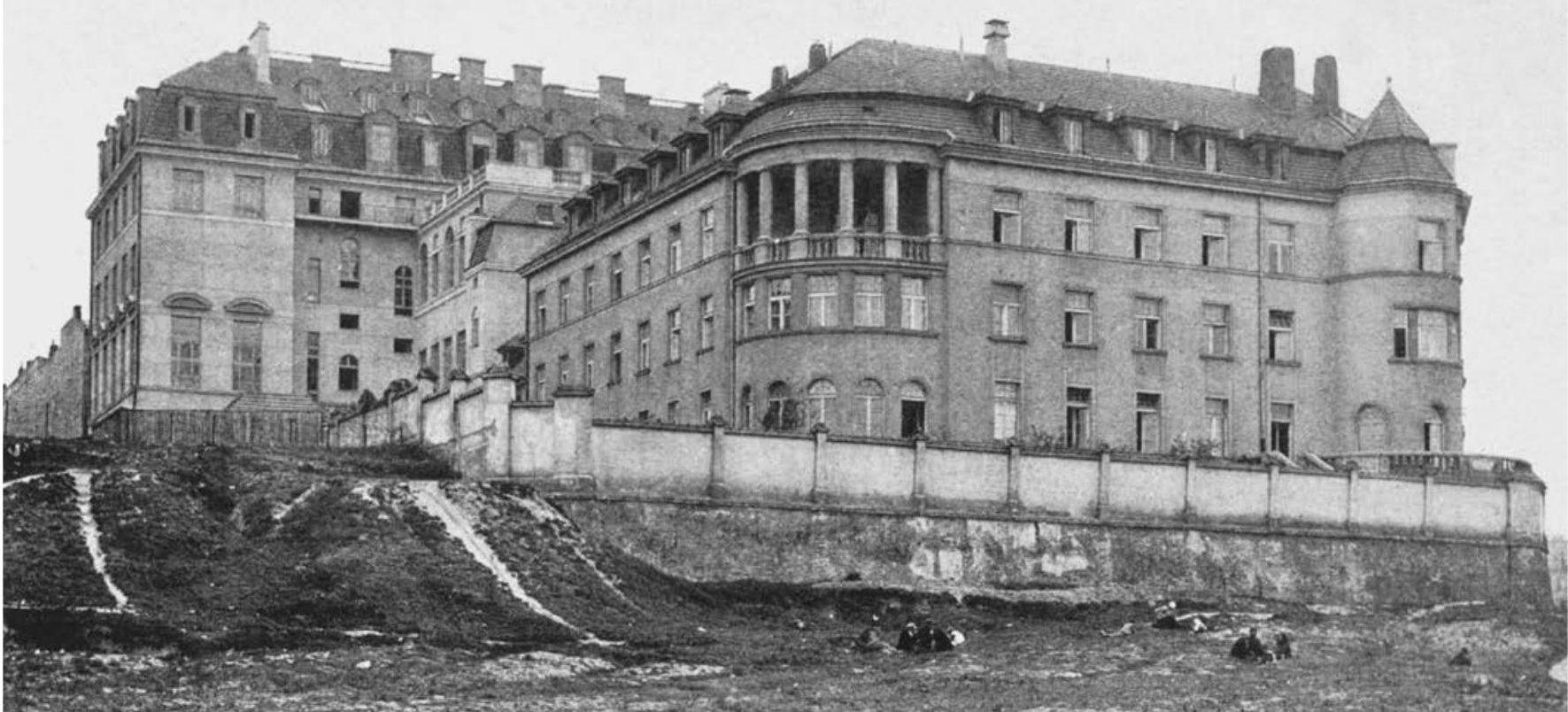

Figura 2: Poder e suntuosidade da nova saúde pública mundial sob os auspícios da Fundação Rockefeller nos anos 1920 (Rockefeller, 1925, p.27) 
Em seu corolário brasileiro, a atuação Rockefeller na saúde pública se veria constantemente cercada de polêmicas e questionada por interesses comerciais velados (principalmente na óptica daqueles que viriam ser suprimidos em sua origem francesa). Sem desconsiderar a dependência brasileira e os benefícios advindos daquele suporte, Arthur Neiva, um dos mais brilhantes sanitaristas brasileiros de todos os tempos, vaticinava:

A Fundação Rockefeller quase três séculos depois vem tratar o nosso jeca e sanear nossa terra. Como é desinteressado o Yankee! [ilegível] Toda a crise do Butantan teve sua origem nos interesses da Standard Oil Company puxando os cordéis aos homens da Fundação Rockefeller. [ilegível] Em discurso em Butantan, denunciei as missões científicas comerciais, travou-se a luta em que sou sempre levado pela desproporção de forças (citado em Faria, 2007, p.136).

No livro em que narram as disputas entre Neiva e Carlos Chagas, os pesquisadores meio que tomam partido dessa via de mão dupla, naturalmente desbalanceada: "os objetivos reais da instituição seriam, de acordo com muitos autores, maximizar os lucros das empresas extrativas e agropecuárias dos norte-americanos e expandir sua supremacia política e ideológica no cenário do imperialismo mundial" (Benchimol, Teixeira, 1993, p.98).

Do outro lado havia absoluta relutância em reconhecer qualquer componente político nas ações patrocinadas pela Fundação Rockefeller por parte de pessoas ligadas a ela. Em São Paulo, todo embate era mediado por Paula Souza, sempre rápido em evocar objetivos puramente científicos das empreitadas. Fazia isso a ponto de, indicado diretor do Serviço Sanitário, despachar do Instituto de Higiene com o intuito de reafirmar a autoridade da ciência sobre a política na nova "era". É crível que acreditasse sinceramente nisso, mas outros, como o senador Oscar Rodrigues Alves, notório representante do clã Rodrigues Alves e médico de formação francesa, atacava com veemência aquilo que considerava um grave conflito de interesses (Faria, 2007). ${ }^{4}$

Em linhas gerais, uma dinâmica histórica que guarda similitude latino-americana (Ramos, 1972). Muito pouco questionada nesse sentido, a Opas, descendente direta da visão estratégia do pan-americanismo de Roosevelt e por longo período dirigida por militares e profissionais ligados à Fundação Rockefeller, sempre esteve à frente de toda pauta política da saúde nesses países (Cueto, 2007) - embora também usualmente disposta no plano discursivo científico.

Um dos legados mais estáveis de todo esse processo, sua própria essência e seu sentido de ser, definiu-se na capacidade de sedimentar e naturalizar no senso comum - popular e técnico a separação do campo assistencial curativo na ordem liberal, fixando na saúde pública a assistência de caráter eminentemente preventivo (um dos principais motivos da afirmação anterior de se tratar de matriz discursiva liberal por excelência). Desde então, cada vez mais se fortaleceu a separação prática, científica e ideológica desses dois sistemas. Para isso, uma característica fundamental consistiu no estímulo a construção, alargamento e apropriação daquela matriz discursiva pelo próprio pensamento periférico. E, realmente, nada mais brasileiro, original - e, diga-se, valoroso - do que as soluções criadas e refinadas pelo Sesp (depois Fundação Sesp) no estabelecimento de uma rede de serviços básicos nos sertões brasileiros (Campos, A., 2006). Muito do que viria a ser novamente apropriado e refinado pelo Programa de Saúde da Família, embora, nesse sentido, história pouco citada e conhecida. 


\section{O movimento de reforma sanitária}

É preciso assumir de início que, apesar de sua alta popularidade na literatura da saúde pública brasileira, a realidade é que a ideia de movimento de reforma sanitária não acumula um suficiente corpo teórico específico para caracterizá-la conceitualmente. Numa leitura acadêmica atenta, expressaria de modo geral um corpo de ideias políticas de referencial progressista que conflui para a defesa de um sistema de saúde público estatal, universal e organizado sobre necessidades de saúde coletivas.

A questão é que a linguagem de reforma sanitária foi desde o início extremamente polissêmica; acabando por se tornar, no senso comum, sinônimo de saúde pública, de seu alter ego saúde coletiva, e, finalmente do próprio Sistema Único de Saúde (SUS) - assim é que todos os profissionais envolvidos no SUS são virtualmente apoiadores automáticos da reforma sanitária. Uma característica refletida nos estudos acadêmicos. Em ampla revisão de literatura, Paim (2008) realmente conclui sobre a representação acadêmica do objeto "reforma sanitária" como sinonímia do SUS. Justamente numa análise em que busca rejeitar esse tipo de interpretação com o propósito da definição primária do conceito de "reforma sanitária" como "revolução do modo de vida" (p.38). Num interessante texto anterior (Paim, 1997), analisa o "movimento sanitário" à luz do debate paradigmático no intuito de abranger a reforma sanitária para muito além dos limites do SUS - mas a realidade é que não deixa de ser um texto autoral, e não de representação coletiva, como aspirado. Vale aqui breve digressão sobre a insistência da ideia de "movimento", puramente teleológica, associada à "reforma sanitária", algo que não encontra sustentação conceitual nem histórica. Para efeito de comparação, Karl Polanyi, um dos pensadores políticos mais importantes do século XX, tem dificuldades em considerar assim o fascismo que se espalhou pelo mundo: “O próprio termo 'movimento' era equivocado, uma vez que implicava uma espécie de alistamento ou participação pessoal de grandes massas. Se houve alguma coisa característica no fascismo foi a sua independência de tais manifestações populares" (Polanyi, 2000, p.277; destaque no original).

Outros problemas se interpõem àquele intento conceitual literalmente revolucionário da reforma sanitária. Talvez o principal seja mesmo o fato de o SUS sempre ter sido postado na alça de mira do discurso da reforma sanitária, fruto inicial do pragmatismo político do Cebes. De fato, a urgência e o esforço em superar o monstro previdenciário na direção de um sistema de saúde único e universal deixava pouco espaço de manobra (Cordeiro, 2004). As efetivas mobilizações sociais orgânicas da reforma sempre giraram em torno da criação do SUS, desde seu texto seminal "A questão democrática na saúde", de Hésio Cordeiro, José Luiz Fiori e Reinaldo Guimarães, defendido no primeiro Simpósio de Política Nacional de Saúde realizado na Câmara dos Deputados em Brasília em 1979 (Cordeiro, 2004; Paim, 2008). Era a "dialética do possível", ou o flanco aberto da "via do parlamento" pela qual tanto participou a Abrasco (Rodriguez Neto, 1997, 2003). Dizia o eminente professor Gastão Campos (1990, p.46) quando na posição de secretário de Saúde: “Na área da saúde, nós filiávamos ao conjunto de forças que vinha lutando pela reforma sanitária, projeto a ser concretizado, segundo nosso ponto de vista, através da implantação do Sistema Único de Saúde" - ressalvado que, efetivamente, um SUS contraliberal. Com efeito, depois da criação do SUS, os ideais avançam, agora inseridos 
em uma visão acadêmica e de práxis que amadurece na Abrasco, eclipsando o pragmatismo social da primeira leitura. Com isso, o intento conceitual deixa de ter materialidade definida para se tornar um conceito de conformação histórica continuada sempre sujeito às disputas estruturais e conjunturais: "Não parece convincente, portanto, aguardar o 'Grande Dia' em que seria declarada, finalmente, a implantação da Reforma Sanitária" (Paim, 1997, p.16; destaque no original).

Mesmo conformada no interior do pensamento de esquerda, a visão de reforma sanitária nunca logrou homogeneidade. Autores que faziam críticas tenazes à ideia que se seguiu à oitava Conferência Nacional de Saúde passam mais à frente a encampá-la sob outro prisma. Ainda assim, numa ebulição intelectual na qual correntes progressistas se altercavam entre visões e mesclas do marxismo-funcionalismo, estruturalista, autonomista, sistêmica ou historicista. Um alento sobreveio em torno da possibilidade de uma práxis mutuamente revolucionária e reformista, agregando um grupo importante de intelectuais para pensar a construção teórica do conceito de "reforma sanitária" fundamentada no marxismo de Gramsci (Teixeira, 1989) é do aprofundamento e objetivação desse paradigma "orgânico" que Paim reclamava acima no confronto com o senso comum do SUS.

Mas a capacidade transformadora do novo paradigma radical esteve sempre contraposta à dificuldade em extrapolar o perímetro acadêmico, e a reforma continuou pragmática sobre o SUS assistencial - como atestam algumas mobilizações sociais isoladas, descritas como "movimentos populares em saúde". Sem nunca conseguir superar o antigo "fantasma da classe ausente", cujo operariado sabidamente sempre clamou por uma assistência do setor privado. ${ }^{5}$ A verdade é que, apesar de hercúleos esforços, a radicalização ressentiu-se da ausência de um exército e de financiamento à altura da Rockefeller Foundation (e Carnegie Foundation, e Kellogg Foundation, e outras).

Com toda extensão e qualidade de estudos e materiais produzidos, o desafio acadêmico do paradigma radical em produzir novo léxico nunca foi menos difícil, ou sem efeitos colaterais. Instado ao novo em assumida intencionalidade política, houve naturalmente uma grande seletividade referencial nos textos acadêmicos que se seguiram, com toda consequência disciplinar que isso representa. Veja-se, por exemplo, a dificuldade de Donnangelo (1975, p.4) em citar a teoria da cidadania de Marshall sem se sentir compelida a explicar-se: "sem que o recurso à tipologia por ele elaborada represente um compromisso com suas concepções teóricas e metodológicas". Realmente, conceito de princípios capitalistas como a garantia à propriedade, a "cidadania" representou uma incômoda pedra no sapato na construção do discurso de esquerda. A mesma situação se repetiu no amparo científico, considerado pelo referencial gramscista como ideológico por natureza. Gastão Campos (2006) deixa visível esse desconforto no tópico metodológico de sua dissertação, "dificuldades na construção de uma metodologia apropriada", no qual, sobre aquele princípio, assume que não haveria ciência ou método em si, e que cada investigação deveria criar seu método adequado. Em desenrolar atual, o conceito internacional de "atenção primária" foi politicamente repensado em "atenção básica". Mas, de novo, não se sustentou em léxico próprio, retomando suas origens alguns anos depois. O que se pode notar é que o elemento vital da ruptura teleológica de um novo modelo de pensamento parece não estar em sua rotinização no senso 
comum, mas na sustentação de sua especificidade ao longo do tempo, isto é, da garantia de independência semântica em relação ao léxico anterior.

Tudo isso foi particularmente frustrante no terreno das práticas; em último caso, o plano elementar da "dialética concreta de situações concretas". Educado a pensar na etérea matriz Rockefeller, de onde quer que se origine, o pensamento contestador nunca conseguiu oferecer reais alternativas ao modelo assistencial que foi construído ao longo do século $\mathrm{XX}$. Concentrado em extenuantes objetivos de um plano político social, pelo menos duas frentes decisivas marcaram passo na radicalização da reforma sanitária. Em primeiro lugar, o cotidiano clínico dos serviços - discernimento dolorosamente despertado pela instituição do PSF e ressurgimento da medicina de família tão ardorosamente combatida pela saúde coletiva (Paim, 1986). O paradigmático "necessidades de saúde", opondo-se à "história natural das doenças", tampouco conseguiu se impor no cotidiano clínico. Não que não se lhe tenha reconhecido a importância clínica, mas em muito porque a clínica é individualizada em sua natureza, vindo a visão coletiva complementá-la, e não substituí-la (Novaes, 1997). Na segunda frente, a desatenção com a gravidade de uma política de ciência, tecnologia e inovação em saúde (CTIS) obstou o aprofundamento e instrumentalização do novo corpo tecnológico pretendido (Guimarães, 2005).

\section{Considerações finais}

Neste ensaio histórico, concluo inicialmente pela propriedade do uso da expressão "ruptura paradigmática", desarmada da pretensão de cientificidade conceitual. O que, em consequência, passa a exigir sua contextualização histórica sincrônica e diacrônica, de forma a relativizar sua radicalidade. No campo da saúde pública, tais rupturas obrigatoriamente se representam nas dimensões científicas e ideológicas, cuja maturação e difusão são ultimadas pela dependência da intencionalidade política.

Sobre essas premissas, assumo a ocorrência de uma gama de novos paradigmas no campo da saúde pública ao longo do século XX. Entretanto, não teriam deixado de representar paradigmas cumulativos sobre a revolução epistêmica global operada pela Fundação Rockefeller com o novo discurso dos centros de saúde distritais e educação sanitária a partir dos anos 1920. Em contraponto político fornecido por Foucault (2000), tratar-se-ia também do início da "era da medicina dos pobres e da força de trabalho" (não por acaso, Geraldo de Paula Souza dedica-se ao estudo da força de trabalho e participada fundação do Instituto de Organização Racional do Trabalho, Idort). De maneira geral, essa matriz discursiva de interstício liberal foi ativamente difundida pelo globo, com forte apelo nas Américas, em arranjos mediados pela cultura, política, capacidade técnica e financeira epocal.

A partir do final dos anos 1970, o sanitarismo brasileiro assumiu posição de vanguarda na resistência a esse discurso (Arouca, 2003), e uma rede intelectual se formou em torno do conceito de "reforma sanitária", definindo-se paradigmaticamente no novo campo da "saúde coletiva". Entretanto, o tempo tem mostrado que a rotinização de um novo senso comum é apenas a ponta do iceberg no desafio de sustentar um novo léxico conceitual independente. Isso, associado à baixa especificidade clínica e à fragilidade estratégica em CTIS, dificulta o distanciamento do discurso da saúde coletiva daquele que busca superar. Enfim, de modo 
geral, o paradigma saúde coletiva/reforma sanitária mantém-se ainda imerso na magnitude do paradigma roquefeleriano, especialmente se considerada a dimensão assistencial. Sem dúvida, Arouca e Jairnilson Paim fornecem as melhores contribuições da saúde coletiva nesse debate.

Num arroubo argumentativo final, todo o raciocínio exposto instiga a pensar que o cenário contemporâneo de grande positividade do setor privado na saúde brasileira pode não ser fruto apenas das forças do capital e do subfinanciamento do SUS. Por sua vez, a histórica defesa dos centros de saúde como porta universal exclusiva de atenção básica não deixa também de acenar paradoxalmente para o reforço da dicotomia público/preventivo e privado/curativo.

Contudo, não resta dúvida sobre a necessidade de maior latência histórica para verdadeira compreensão e dimensionamento das rupturas semânticas, científicas e sociais experimentadas atualmente. O certo é que este século XXI irrompe-se para uma ruptura epistemológica holística, cada vez mais claramente apontada para a "mercadorização" irrestrita da vida, para a qual deverão ser pensadas novas estratégias de saúde pública que realmente supere a arraigada e etérea semântica atual. Fica a pergunta: para isso, será necessário aprender a pensar em javanês?

\section{NOTAS}

${ }^{1}$ Há aqui um obstáculo finalístico provavelmente intransponível, que diz respeito ao problema filosófico da "demarcação científica", isto é, o que pode ou não ser considerado "científico" (Lakatos, 1998). Algumas correntes negam qualquer possibilidade de solução, com é o caso do conhecido "programa forte" (Pestre, 1996). Thomas Kuhn, que em princípio os via numa linha iconoclasta, enfim capitulou em posição semelhante (Kuhn, 2006b. Ver capítulo 5: "O problema com a filosofia histórica das ciências"). De uma visada marxista, pelo contrário, conceitos, ideias e mesmo o corpo científico em geral são vistos como expressões próprias de um contexto ideológico (Portelli, 2002).

${ }^{2}$ Revela que por isso chegava a receber convites para eventos de natureza política. Ver o capítulo/entrevista: "Um debate com Thomas S. Kuhn" (Kuhn, 2006b).

3 Ver a parte 1: "Reconcebendo as revoluções científicas".

${ }^{4}$ Ver p.91 e também o discurso de Oscar Rodrigues Alves. In: Anais do Senado, $80^{a}$ sessão ordinária de 22 de dezembro de 1924, p.688 (citado em Nadai, 1987, p.222).

${ }^{5}$ A distância entre a academia e o operariado está bem ilustrada na biografia de Lula, que conta como percebiam os estudantes infiltrados na política operária. Por exemplo, ao corrigir o português nos textos do sindicato ou quando uma trabalhadora bebia aguardente no bar, comportamento incongruente com a cultura da mulher operária da época. Em 1978, questionado se os operários e estudantes não deveriam se unir, sua resposta não poderia ser mais clara: "Sem querer ofender os estudantes - talvez o meu baixo grau de cultura ... talvez essa minha desinformação que me leve a ser assim - mas eu acho que a melhor maneira de os estudantes ajudarem a classe trabalhadora seria eles ficarem dentro das universidades" (Paraná, 2008, p.446).

\section{REFERÊNCIAS}

ARAÚJO, Valdei Lopes.

História dos conceitos: problemas e desafios para uma releitura da modernidade ibérica. Almanack Braziliense, n.7. Disponível em: http://www. revistas.usp.br/alb/article/view/11680. Acesso em: 9 mar. 2015. maio 2008.

AROUCA, Sergio.

O dilema preventivista: contribuição para a compreensão e crítica da medicina preventiva. São Paulo: Unesp; Rio de Janeiro: Editora Fiocruz. 2003.

ATKIN, Philip A.

A paradigm shift in the medical literature. British Medical Journal, v.325, n.7378, p.1450-1451.

2002. 
BENCHIMOL, Jaime Larry; TEIXEIRA, Luiz Antonio.

Cobras, lagartos e outros bichos: uma história comparada dos institutos Oswaldo Cruz e Butantan. Rio de Janeiro: Editora UFRJ. 1993.

BENTIVOGLIO, Julio.

A história conceitual de Reinhart Koselleck. Dimensões, n.24, p.114-134. 2010.

BERLINGUER, Giovanni; TEIXEIRA, Sonia Maria Fleury; CAMPOS, Gastão Wagner (Org.). Reforma sanitária: Itália e Brasil. São Paulo: Hucitec; Cebes. 1988.

BROWN, E. Richard.

Public health in imperialism: early Rockefeller programs at home and abroad. American Journal of Public Health, v.66, n.9, p.897-903. 1976.

CAMPOS, André Luiz Vieira de.

Políticas internacionais de saúde na Era Vargas: o Serviço Especial de Saúde Pública, 1942-1960. Rio de Janeiro: Editora Fiocruz. 2006.

CAMPOS, Gastão Wagner de Souza.

Os médicos e a política de saúde: entre a estatização e o empresariamento: a defesa da prática liberal da medicina. São Paulo: Hucitec. 2006.

CAMPOS, Gastão Wagner de Souza. Reflexões sobre uma proposta de gestão de sistema local de saúde. Revista de Administração Pública, v.24, n.4, p.45-52. 1990.

CANDIDO, Antonio.

Radicalismos. Estudos Avançados, v.4, n.8, p.4-18. 1988.

CASTRO SANTOS, Luiz Antonio; FARIA, Lina. O ensino da saúde pública no Brasil: os primeiros tempos no Rio de Janeiro. Trabalho, Educação e Saúde, v.4, n.2, p.291-324. 2006.

CASTRO SANTOS, Luiz Antonio; FARIA, Lina. Os primeiros centros de saúde nos Estados Unidos e no Brasil: um estudo comparativo. Teoria e Pesquisa, n.40-41, p.137-181. 2002.

CHAVES, Mário M.

Saúde e sistemas. Rio de Janeiro: FGV Editora. 1972.

CORDEIRO, Hésio.

SUS: Sistema Único de Saúde. Rio de Janeiro: Editora Universidade Estácio de Sá. 2004.

CUETO, Marcos.

O valor da saúde: história da Organização Panamericana da Saúde. Rio de Janeiro: Editora Fiocruz. 2007.

DONNANGELO, Maria Cecília Ferro.

Medicina e sociedade: o médico e seu mercado de trabalho. São Paulo: Pioneira. 1975.
FARIA, Lina.

Saúde e política: a Fundação Rockefeller e seus parceiros em São Paulo. Rio de Janeiro: Editora Fiocruz. 2007.

FEUERWERKER, Laura Camargo. Mudanças na educação médica e residência médica no Brasil. São Paulo: Hucitec; Rede Unida. 1998.

FLEXNER, Abraham.

Medical education in the United States and Canada: a report to the Carnegie Foundation for the Advancement of Teaching. New York: Carnegie Foundation for the Advancement of Teaching. 1910.

FONSECA, Cristina Maria Oliveira.

Saúde no governo Vargas (1930-45): dualidade institucional de um bem público. Rio de Janeiro: Editora Fiocruz. 2007.

FOUCAULT, Michel.

O nascimento da medicina social. In: Foucault, Michel. Microfísica do poder. Rio de Janeiro: Graal. p.79-98. 2000.

FRAGA, Clementino.

Vida e obra de Oswaldo Cruz. Rio de Janeiro: Editora Fiocruz. 2005.

GALLO, Eduardo (Org.).

Razão e planejamento: reflexões sobre política, estratégia e liberdade. Rio de Janeiro: Hucitec; Abrasco. 1995.

GINZBURG, Carlo.

Sinais: raízes de um paradigma indiciário. In: Ginzburg, Carlo. Mitos, emblemas, sinais: morfologia e história. São Paulo: Companhia das Letras. p.143-180. 1989.

GUIMARÃES, Reinaldo.

Ciência, tecnologia e inovação: um paradoxo na reforma sanitária. In: Lima, Nísia Trindade (Org.). Saúde e democracia: história e perspectivas do SUS. Rio de Janeiro: Editora Fiocruz. p.235-256. 2005.

HOCHMAN, Gilberto.

A era do saneamento: as bases da política de saúde pública no Brasil. São Paulo: Hucitec; Anpocs. 1998.

IGLEHART, John K.

Connected health: emerging disruptive technologies. Health Affairs, v.33, n.2, p.190. 2014.

INFORME...

Informe Dawson sobre el futuro de los servicios medicos y afines. Traducción al castellano del Dawson Report on the future provision of medical and allied services. Washington: Organización Panamericana de la Salud. 1964. 
KOSELLECK, Reinhart.

Uma história dos conceitos: problemas teóricos e práticos. Estudos Históricos, v.5, n.10, p.134-146. 1992.

KUHN, Thomas Samuel.

A estrutura das revoluções científicas. São Paulo: Perspectiva. 2006a.

KUHN, Thomas Samuel.

O caminho desde a estrutura. São Paulo: Unesp. 2006b.

KUHN, Thomas Samuel.

Reflexões sobre os meus críticos. In: Lakatos, Imre; Musgrave, Alan (Org.). A crítica e o desenvolvimento do conhecimento. São Paulo: Cultrix; Edusp. p.285-343. 1979.

LAKATOS, Imre.

História da ciência e suas reconstruções racionais e outros ensaios. Lisboa: Edições 70. 1998.

LIMA, Nísia Trindade; FONSECA, Cristina Oliveira; HOCHMAN, Gilberto.

A saúde na construção do estado nacional no Brasil: reforma sanitária em perspectiva histórica. In: Lima, Nísia Trindade (Org.). Saúde e democracia: história e perspectivas do SUS. Rio de Janeiro: Editora Fiocruz. p.27-58. 2005.

MARINHO, Maria Gabriela S.M.C.

Norte-americanos no Brasil: uma história da Fundação Rockefeller na Universidade de São Paulo, 1934-1952. Bragança Paulista: Universidade São Francisco; Campinas: Autores Associados. 2001.

MASCARENHAS, Rodolfo dos Santos; WILSON D.; BOURROUL, G.P.

$\mathrm{O}$ ensino da medicina preventiva em escolas de medicina. Arquivos da Faculdade de Higiene, v.1516, p.17-24. 1961.

MASTERMAN, Margaret.

A natureza de um paradigma. In: Lakatos, Imre; Musgrave, Alan (Org.). A crítica e o desenvolvimento do conhecimento. São Paulo: Cultrix; Edusp. p.72-108. 1979.

MELLO, Guilherme Arantes.

Pensamento clássico da saúde pública paulista na era dos centros de saúde e educação sanitária. Revista de Saúde Pública, v.46, n.4, p.747-750. 2012.

MELLO, Guilherme Arantes; BONFIM, José Ruben Alcântara.

Um sanitarista chamado Walter Leser. Ciência e Saúde Coletiva, v.20, n.9, p.2749-2754. 2015.

MELLO, Guilherme Arantes; FONTANELLA, Bruno José Barcellos; DEMARZO, Marcelo Marcos Piva. Atenção básica e atenção primária à saúde: origens e diferenças conceituais. Revista de APS, v.12, n.2, p.204-213. 2009.
MELLO, Guilherme Arantes; VIANA, Ana Luiza d'Ávila.

Uma história de conceitos na saúde pública: integralidade, coordenação, descentralização, regionalização e universalidade. História,

Ciências, Saúde - Manguinhos, v.19, n.4, p.12191240. 2012.

MELLO, Guilherme Arantes; VIANA, Ana Luiza d'Ávila.

Centros de saúde: ciência e ideologia na reordenação da saúde pública no século XX.

História, Ciências, Saúde-Manguinhos, v.18, n.4, p.1131-1149. 2011.

MORIN, Edgar.

Introdução ao pensamento complexo. Porto Alegre: Sulina. 2011.

NADAI, Elza.

Ideologia do progresso e ensino superior (São Paulo 1891-1934). São Paulo: Loyola. 1987.

NOVAES, Ricardo Lafetá.

Do biológico e do social: um pequeno balanço. In: Fleury, Sonia (Org.). Saúde e democracia: a luta do Cebes. São Paulo: Lemos. p.205-225. 1997.

NUNES, Everardo (Org.).

O pensamento social em saúde na América Latina: revisitando Juan César García. São Paulo: Cortez. 1989.

PAIM, Jairnilson.

Reforma sanitária brasileira: contribuição para a compreensão e crítica. Salvador: Edufba; Rio de Janeiro: Editora Fiocruz. 2008.

PAIM, Jairnilson.

Bases conceituais da reforma sanitária brasileira. In: Fleury, Sonia (Org.). Saúde e democracia: a luta do Cebes. São Paulo: Lemos. p.11-24. 1997.

PAIM, Jairnilson.

Saúde, crises e reformas. Salvador: Centro Editorial e Didático da UFBA. 1986.

PAIM, Jairnilson; ALMEIDA FILHO, Naomar. Paradigma e crises: a crise da saúde pública e a utopia da saúde coletiva. Salvador: Casa da Qualidade. 2000.

PAIM, Jairnilson; ALMEIDA FILHO, Naomar. Saúde coletiva: uma "nova saúde pública" ou campo aberto a novos paradigmas? Revista de Saúde Pública, v.32, n.4, p.299-316. 1998.

PARANÁ, Denise.

Lula: o filho do Brasil. São Paulo: Perseu Abramo. 2008.

PESTRE, Dominique.

Por uma história social e cultural das ciências: novas definições, novos objetos, novas abordagens. Cadernos IG-Unicamp, v.6, n.1, p.3-56. 1996. 
PLSEK, Paul.

Redesigning health care with insights from the science of complex adaptive systems. In: Institute of Medicine (US). Crossing the quality chasm. Washington: National Academy Press. p.309-322. 2003.

POLANYI, Karl.

A grande transformação: as origens de nossa época. Rio de Janeiro: Elsevier. 2000.

PORTELLI, Hugues.

Gramsci e o bloco histórico. Rio de Janeiro: Paz e Terra. 2002.

RAMOS, Reinaldo.

A integração sanitária: doutrina e prática. Tese (livre-docência) - Faculdade de Saúde Pública, Universidade de São Paulo, São Paulo. 1972.

\section{ROCKEFELLER FOUNDATION.}

International Health Board. Annual Report. New York: Rockefeller Foundation. 1925.

RODRIGUEZ NETO, Eleutério.

Saúde: promessas e limites da Constituição. Rio de Janeiro: Editora Fiocruz. 2003.

RODRIGUEZ Neto, Eleutério.

A via do parlamento. In: Fleury, Sonia (Org.). Saúde e democracia: a luta do Cebes. São Paulo: Lemos. p.63-91. 1997.

SANTOS, Boaventura.

Um discurso sobre as ciências. São Paulo: Cortez. 2006.

SOUZA, Geraldo de Paula. Seguro social e higiene pública. Arquivos de Higiene, v.8, p.263-270. 1938.
SOUZA, Geraldo de Paula; VIEIRA, Francisco Borges.

Centro de saúde: "eixo" de organização sanitária. Boletim do Instituto de Higiene de São Paulo, n.59. 1936.

TARRIDE, Mario.

Saúde pública: uma complexidade anunciada. Rio de Janeiro: Editora Fiocruz. 1998.

TEIXEIRA, Sonia M. Fleury (Org.).

Reforma sanitária: em busca de uma teoria. São Paulo: Cortez; Rio de Janeiro: Abrasco. 1989.

TESTA, Mario.

Pensar em saúde. Porto Alegre: Artes Médicas; Rio de Janeiro: Abrasco. 1992.

VASCONCELLOS, Maria da Penha. Memórias da saúde pública: a fotografia como testemunha. São Paulo: Hucitec. 1995.

VIANA, Ana Luiza; DAL POZ, Mário. A reforma do sistema de saúde no Brasil o Programa de Saúde da Família. Physis, v.15, supl., p.225-264. 2004.

\section{WINSLOW, Charles-Edward.}

The evolution and significance of the modern public health campaign. New Haven: Yale University Press. 1923.

ZERHOUNI, Elias

Translational and clinical science: time for a New Vision. The New England Journal of Medicine, v.353, n.15, p.1621-1623. 2005. 